\title{
Matrix-assisted laser desorption/ionization time of flight mass spectrometry for comprehensive indexing of East African ixodid tick species
}

Julian Rothen ${ }^{2,3^{*}+}$, Naftaly Githaka ${ }^{1 \dagger}$, Esther G. Kanduma ${ }^{6,7}$, Cassandra Olds $^{5}$, Valentin Pflüger ${ }^{4}$, Stephen Mwaura ${ }^{1}$, Richard P. Bishop ${ }^{1}$ and Claudia Daubenberger ${ }^{2,3}$

\begin{abstract}
Background: The tick population of Africa includes several important genera belonging to the family Ixodidae. Many of these ticks are vectors of protozoan and rickettsial pathogens including Theileria parva that causes East Coast fever, a debilitating cattle disease endemic to eastern, central and southern Africa. Effective surveillance of tick-borne pathogens depends on accurate identification and mapping of their tick vectors. A simple and reproducible technique for rapid and reliable differentiation of large numbers of closely related field-collected ticks, which are often difficult and tedious to discriminate purely by morphology, will be an essential component of this strategy. Matrix-assisted laser desorption/ionization time of flight mass spectrometry (MALDI-TOF MS) is increasingly becoming a useful tool in arthropod identification and has the potential to overcome the limitations of classical morphology-based species identification. In this study, we applied MALDI-TOF MS to a collection of laboratory and field ticks found in Eastern Africa. The objective was to determine the utility of this proteomic tool for reliable species identification of closely related afrotropical ticks.
\end{abstract}

Methods: A total of 398 ixodid ticks from laboratory maintained colonies, extracted from the hides of animals or systematically collected from vegetation in Kenya, Sudan and Zimbabwe were analyzed in the present investigation. The cytochrome c oxidase I (COI) genes from 33 specimens were sequenced to confirm the tentatively assigned specimen taxa identity on the basis of morphological analyses. Subsequently, the legs of ticks were homogenized and analyzed by MALDI-TOF MS. A collection of reference mass spectra, based on the mass profiles of four individual ticks per species, was developed and deposited in the spectral database SARAMIS ${ }^{\mathrm{TM}}$. The ability of these superspectra (SSp.) to identify and reliably validate a set of ticks was demonstrated using the remaining individual 333 ticks.

(Continued on next page)

\footnotetext{
* Correspondence: julian.rothen@unibas.ch

${ }^{\dagger}$ Equal contributors

${ }^{2}$ Department of Medical Parasitology and Infection Biology, Clinical

Immunology Unit, Swiss Tropical and Public Health Institute (Swiss TPH),

Socinstr. 57, CH 4002 Basel, Switzerland

${ }^{3}$ University of Basel, Petersplatz 1, CH 4003 Basel, Switzerland

Full list of author information is available at the end of the article
} 
(Continued from previous page)

Results: Ultimately, ten different tick species within the genera Amblyomma, Hyalomma, Rhipicephalus and Rhipicephalus (Boophilus) based on molecular COI typing and morphology were included into the study analysis. The robustness of the 12 distinct SSp. developed here proved to be very high, with 319 out of 333 ticks used for validation identified correctly at species level. Moreover, these novel SSp. allowed for diagnostic specificity of $99.7 \%$. The failure of species identification for 14 ticks was directly linked to low quality mass spectra, most likely due to poor specimen quality that was received in the laboratory before sample preparation.

Conclusions: Our results are consistent with earlier studies demonstrating the potential of MALDI-TOF MS as a reliable tool for differentiating ticks originating from the field, especially females that are difficult to identify after blood feeding. This work provides further evidence of the utility of MALDI-TOF MS to identify morphologically and genetically highly similar tick species and indicates the potential of this tool for large-scale monitoring of tick populations, species distributions and host preferences.

Keywords: MALDI-TOF MS, Ticks, Species identification, Vector epidemiology, COI, Amblyomma, Boophilus, Hyalomma, Rhipicephalus

\section{Background}

As obligate hematophagous organisms, ticks can acquire and transmit pathogenic microorganisms such as eukaryotic parasites, bacteria, viruses and fungi both through vertical transmission or when feeding on their hosts [1]. Tick-borne diseases (TBDs) cause significant economic losses to the cattle industry in tropical and subtropical regions of the world [2]. Some tick species are capable of building up focally highly dense populations, causing additional production losses in farm animals from irritation, skin damage and accompanying chronic inflammation, blood loss and in some cases, secondary infections [1, 3]. In most of Eastern Africa, several ixodid tick species share overlapping habitats and multiple tick infestations in livestock is frequently observed [4]. The control of TBDs can be improved and targeted appropriately by accurate monitoring of tick vectors. This has traditionally been done by examining morphological features using a light microscope, and with the aid of taxonomical descriptions and illustrations [4, 5]. Unfortunately, the expert knowledge required for this task is rare in most settings where TBDs are endemic [4]. In addition, damaged or immature tick stages, or replete female ticks are often difficult to identify accurately based on morphological features alone [6]. Molecular approaches like sequencing of the cytochrome $c$ oxidase subunit I (COI), the $12 \mathrm{~S}$ rDNA or the internal transcribed spacer 2 (ITS2) can overcome the limitations of conventional tick taxonomy. Due to the labor, time and costs involved in DNA extraction, PCR amplification, purification and nucleotide sequencing, this approach is typically limited to well-equipped laboratories $[7,8]$. When COI, $12 \mathrm{~S}$ or ITS reference sequences are scarce or missing from public nucleotide databases, it is difficult to conclusively resolve the species level thus non-identical sequences may remain unidentifiable [9]. Additionally, public databases are known to sometimes contain misidentified species, and sequences showing errors or obtained from contaminated samples resulting in inaccurate classification [10]. Hence, a marker-based identification system is useful to supplement morphological species identification and support taxonomy, either as corroborating evidence for existing hypotheses or as a starting point for further testing using additional techniques [11].

Matrix assisted laser desorption/ionization time of flight mass spectrometry (MALDI-TOF MS) is emerging as an alternative to both morphology and PCR-based typing for identifying disease vectors such as mosquitoes $[12,13]$, tsetse fly [14] and ticks $[15,16]$. MALDI-TOF MS makes use of a small quantity of whole organism material, and thus can identify damaged tick specimens or immature stages [16]. As a diagnostic technique, MALDI-TOF MS is both cost-effective and rapid, can be performed without in depth technical knowledge and the data results have been found to be highly reproducible [17]. In disease endemic areas, MALDI-TOF MS could assist in resolving questions that are difficult to answer with traditional morphological or current molecular based typing methods. For example, the unclear epidemiological status of the two closely related tick species Rhipicephalus simus and Rhipicephalus praetextatus in Kenya, where COI sequencing of field samples strongly indicates occurrence of $R$. simus, although this species is currently thought to be confined to Southern Africa [4]. It is possible that ixodid species other than Rhipicephalus appendiculatus may transmit Theileria parva in Eastern Africa, because number of Rhipicephalus species on domestic animals is greater than previously thought (E. Kanduma and R. Bishop, unpublished data), but more in-depth, higher resolution analyses of both tick vectors and the pathogens they transmit are necessary to confirm this. Moreover, the vector of Theileria sp. (buffalo) a species that is infective to cattle 
at livestock-wildlife interface with unknown consequences in respect of pathology, especially in the coinfection situation is currently unknown [18]. These and similar questions require resolution especially in the context of the epidemiology of theileriosis at the livestock-wildlife interface [19, 20]. Methods endowed with higher resolution and throughput ideally for both the tick vectors and the pathogens that they transmit will be required in future to follow tick borne disease epidemiology, particularly in times of rapid climate changes in these regions [18]. The objective of this study was to extend the application of MALDI-TOF as a highthroughput tick typing method $[15,16]$ to a collection of Afrotropical ixodid ticks obtained from Eastern Africa. We envisage that the data from our tick collection will serve as a reference for indexing the multiple ixodid tick species that frequently occur sympatrically in Africa.

\section{Methods}

\section{Laboratory reared ticks}

A total of 398 adult ticks built the basis of this study. One hundred fifty six ticks were obtained from colonies that had been bred and maintained as closed genetic stocks at the International Livestock Research Institute (ILRI) Tick Unit. These were reared and managed as described by Bailey [21] and Irvin and Brocklesby [22]. With the exception of a Hyalomma sp. whose identity was uncertain until recently, the history and identity of all other tick species kept at the unit were well documented (Table 1). The laboratory maintained colonies ticks consisted of Ambylomma variegatum (21), Hyalomma sp. (16), R. appendiculatus (40 (Muguga colony) and 9 (Kiambu colony)), Rhipicephalus (Boophilus) decoloratus (22), Rhipicephalus (Boophilus) microplus (21) and Rhipicephalus evertsi evertsi (27). Ticks were transferred to $70 \%$ ethanol and shipped at room temperature to Basel for the MALDI-TOF MS analysis and genomic DNA extraction.

\section{Field ticks and identification by morphological characteristics}

Two hundred forty two field ticks were either plucked directly from animal hosts (cattle/sheep) or were collected from pastures/vegetation. One hundred sixty of these ticks were collected 2014 at various sites in Kenya (Fig. 1). The remaining 82 specimens were collected from multiple localities within East Africa during a study investigating the population structure of $R$. appendiculatus in the field [23] (Fig. 1). Ticks were assigned to sex and species as described by Hoogstraal (1956) and Walker (2000 and 2003) $[4,5]$ and stored in $70 \%$ ethanol and kept at $4{ }^{\circ} \mathrm{C}$ prior to shipping to Basel. Due to the high proportion (242/398) of field ticks and the inclusion of both male and female specimens, we expected our collection to reliably reflect intraspecies physiological and molecular diversity.

\section{Molecular $\mathrm{COI}$ gene typing \\ DNA extraction \& $P C R$}

To confirm the morphologically assigned species identities of field ticks and to check for potential molecular differences to laboratory ticks, specimens of both origins were subjected to molecular analysis. A tick was randomly chosen from the library and thoroughly rinsed with distilled water in order to remove any ethanol residues. The tick legs were detached with a scalpel and stored in $70 \%$ ethanol for later MALDI-TOF MS analysis. The tick body was transferred to a $1.5 \mathrm{ml}$ microcentrifuge tube and placed in liquid nitrogen for $5 \mathrm{~min}$. Using a polypropylene pestle (Sigma-Aldrich), the frozen tick body was thoroughly grinded to powder. Whole genomic DNA was extracted using the QIAGEN $^{\bullet}$ DNeasy $^{\circ}$ Blood E Tissue Kit (Qiagen GmbH, Germany). One hundred eighty microliter buffer ATL and $20 \mu$ proteinase K were added to the grinded tick body and the mixture incubated overnight at $56{ }^{\circ} \mathrm{C}$ to ensure complete lysis of the tissue. The further extraction steps were carried out according to the manufacturers' protocol. The final concentration of extracted gDNA was determined with a spectrophotometer (WPA Lightwave II, Biochrom). Cytochrome $c$ oxidase subunit I (COI) gene sequences of individual ticks were obtained by PCR amplification using the forward primer LCO149021 (5'-GGTCAACAAATCATA AAGATATTGG-3') and reverse primer HC02198 (5' TA AACTTCAGGGTGACCAAAAAATCA-3') [24]. PCR was performed in a $50 \mu \mathrm{l}$ reaction consisting of $5 \mu \mathrm{l} 10 \times \mathrm{PCR}$ Buffer (containing $10 \mathrm{mM} \mathrm{MgCl}$ ), $1 \mu \mathrm{l}$ dNTP mix, $1 \mu \mathrm{l}$ $\mathrm{MgCl}_{2}, 2.5 \mathrm{U}$ HotStarTaq DNA Polymerase (Qiagen $\mathrm{GmbH}$, Germany), $1 \mu \mathrm{l}$ each of forward and reverse primers and 25 to $500 \mathrm{ng}$ of tick gDNA as a template. The final volume of the reaction mixture was made up to $50 \mu \mathrm{l}$ with nucleasefree water (Thermo Scientific, Germany). The PCR conditions consisted of an initial heat activation step at $95{ }^{\circ} \mathrm{C}$ for 15 min followed by 35 cycles of denaturation at $94{ }^{\circ} \mathrm{C}$ for $1 \mathrm{~min}$, annealing at $45{ }^{\circ} \mathrm{C}$ for $1 \mathrm{~min}$ and extension at $72{ }^{\circ} \mathrm{C}$ for $1 \mathrm{~min}$. The final extension was performed for $10 \mathrm{~min}$ at $72{ }^{\circ} \mathrm{C}$. Per run, between 5 to 15 reactions were amplified, including two reactions where the gDNA template was omitted and compensated with nuclease-free water, serving as negative controls. The quality of the PCR products was determined by running $5 \mu \mathrm{l}$ of stained (DNA-Dye NonTox, PanReac/AppliChem) DNA on a $1.0 \%$ agarose gel. The bands were visualized and examined with the GelDoc ${ }^{\mathrm{Tm}} \mathrm{EZ}$ Imager (BioRAD). The amplified COI products were purified using the QIAquick PCR Purification Kit (Qiagen $\mathrm{GmbH}$, Germany) following the manufacturers' protocol. DNA samples were eluted with $40 \mu$ l elution buffer (10 mM TrisCl). The COI gene was sequenced using the gene specific forward and reverse primer pair used for PCR amplification at Microsynth AG, Switzerland. 
Table 1 Overview of 398 ticks that built the basis of this study

\begin{tabular}{|c|c|c|c|c|}
\hline Morphologically assigned species name & Quantity & Sex & Geographical origin & Source \\
\hline Amblyomma gemma & 21 & $4 \mathrm{~F}, 15 \mathrm{M}, 2 \mathrm{ND}$ & Kenya & Vegetation \& Animal \\
\hline Amblyomma hebraeum & 4 & $2 \mathrm{~F}, 1 \mathrm{M}, 1 \mathrm{ND}$ & Zimbabwe & Vegetation \\
\hline Amblyomma variegatum & 21 & $4 \mathrm{~F}, 15 \mathrm{M}, 2 \mathrm{ND}$ & Kenya & Lab colony \\
\hline Amblyomma variegatum & 19 & $5 \mathrm{~F}, 14 \mathrm{M}$ & Kenya & Vegetation \& Animal \\
\hline Hyalomma anatolicum anatolicum & 13 & $10 \mathrm{~F}, 1 \mathrm{M}, 2 \mathrm{ND}$ & Sudan & Vegetation \\
\hline Hyalomma dromedarii & 3 & $2 \mathrm{M}, 1 \mathrm{ND}$ & Kenya & Vegetation \& Animal \\
\hline Hyalomma marginatum rufipes & 18 & $5 \mathrm{~F}, 11 \mathrm{M}, 2 \mathrm{ND}$ & Kenya & Vegetation \& Animal \\
\hline Hyalomma truncatum & 14 & $5 \mathrm{~F}, 6 \mathrm{M}, 3 \mathrm{ND}$ & Kenya & Vegetation \& Animal \\
\hline Hyalomma sp. & 16 & $8 \mathrm{~F}, 6 \mathrm{M}, 2 \mathrm{ND}$ & Kenya & Lab colony \\
\hline Rhipicephalus (Boophilus) decoloratus & 22 & $21 \mathrm{~F}, 1 \mathrm{M}$ & Kenya & Lab colony \\
\hline Rhipicephalus (Boophilus) decoloratus & 19 & $19 \mathrm{~F}$ & Kenya \& Sudan & Animal \\
\hline Rhipicephalus (Boophilus) microplus & 21 & $21 \mathrm{~F}$ & Kenya & Lab colony \\
\hline Rhipicephalus (Boophilus) microplus & 3 & $3 F$ & Kenya & Animal \\
\hline Rhipicephalus appendiculatus & 40 & $16 \mathrm{~F}, 23 \mathrm{M}, 1 \mathrm{ND}$ & Kenya & Lab colony (Muguga) \\
\hline Rhipicephalus appendiculatus & 38 & $15 \mathrm{~F}, 22 \mathrm{M}, 1 \mathrm{ND}$ & Kenya & Vegetation \& Animal \\
\hline Rhipicephalus appendiculatus & 9 & $8 \mathrm{~F}, 1 \mathrm{ND}$ & Kenya & Lab colony (Kiambu) \\
\hline Rhipicephalus evertsi evertsi & 27 & $10 \mathrm{~F}, 16 \mathrm{M}, 1 \mathrm{ND}$ & Kenya & Lab colony \\
\hline Rhipicephalus evertsi evertsi & 28 & $7 \mathrm{~F}, 20 \mathrm{M}, 1 \mathrm{ND}$ & Kenya & Vegetation \& Animal \\
\hline Rhipicephalus praetextatus & 8 & $5 \mathrm{~F}, 2 \mathrm{M}, 1 \mathrm{ND}$ & Kenya & Vegetation \& Animal \\
\hline Rhipicephalus pulchellus & 37 & $21 \mathrm{~F}, 14 \mathrm{M}, 2 \mathrm{ND}$ & Kenya & Vegetation \& Animal \\
\hline Rhipicephalus simus & 17 & $8 \mathrm{~F}, 7 \mathrm{M}, 2 \mathrm{ND}$ & Kenya & Vegetation \& Animal \\
\hline Total & 398 & & & \\
\hline
\end{tabular}

ND sex not determined, $M$ male, $F$ female

\section{Data analysis: sequence editing and multiple alignments}

COI sequence chromatograms were visually inspected and manually edited using Seqtrace [25]. Using the Molecular Evolutionary Genetic Analysis (MEGA) software version 6.0 [26], consensus sequences were generated from a forward and reverse sequence for each of the COI PCR products. Species identity was confirmed by matching of the consensus sequences with reference data deposited in the NCBI GenBank [27] and/or the BOLD database [28], a barcoding database that is a component of the Tree of Life project and contains only COI nucleotide sequences. A positive match with a GenBank record was defined as more than $95 \%$ query coverage and $\geq 97 \%$ identity. A positive match with a record on BOLD was declared at identity values $\geq 97 \%$. Multiple sequence alignment analysis of all consensus sequences was performed using the MUSCLE tool in MEGA. The nucleotide sequences were trimmed to around $680 \mathrm{bp}$ and the phylogenetic analyses computed based on maximum likelihood algorithm and the tree file exported to FigTree [29] for final editing.

\section{MALDI-TOF MS analysis of ticks Sample preparation}

The sample processing protocol has been adopted from previous studies $[15,30]$ and modified accordingly. Specimens were removed from the library, rinsed once with distilled water and dried on absorbent paper. Depending on the size of the tick, two to eight legs were detached with a scalpel and placed in a $1.5 \mathrm{ml}$ microcentrifuge tube containing $10 \mu \mathrm{l}$ of $25 \%$ formic acid. The samples were homogenized using a stainless steel micropestle (LLG Labware, Switzerland) powered by a portable drilling machine for $30 \mathrm{~s}$. The homogenate was then centrifuged at 10,000 rpm for $1 \mathrm{~min}$ and $1 \mu \mathrm{l}$ of the supernatant transferred into a microcentrifuge tube containing $8 \mu \mathrm{l}$ of matrix solution (saturated sinapinic acid, $60 \%$ acetonitrile, $40 \%$ high-performance liquid chromatography (HPLC)-grade water and $0.3 \%$ trifluoroacetic acid). After thoroughly mixing, the solution was spotted in quadruplicates $(1 \mu \mathrm{l}$ each) on a steel target plate (Mabritec AG, Basel, Switzerland). The spots were allowed to dry for several minutes until crystallization of the matrix/analyte mixture was complete 


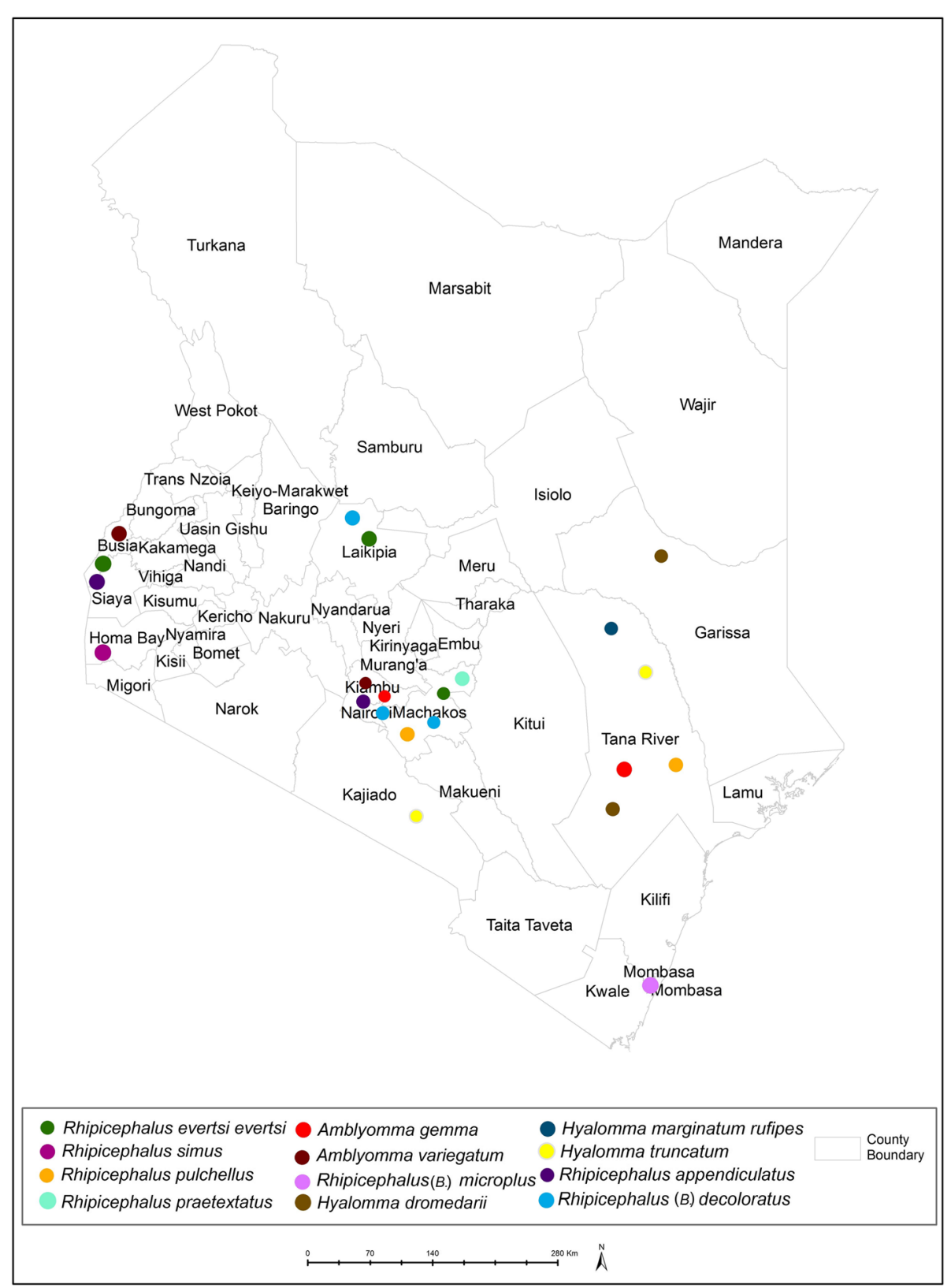

Fig. 1 Geographical origin of ticks used for MALDI-TOF MS analysis in Kenya. The collection sites of the ambiguous Hyalomma species and the specimens obtained from outside Kenya are not shown

and the target plate thereafter transferred to the MALDITOF MS instrument.

\section{MALDI-TOF parameters}

The MS measurements were carried out using a MALDI-TOF Mass Spectrometry Axima $^{\mathrm{at}}$ Confidence machine (Shimadzu-Biotech Corp., Kyoto, Japan) with detection in the linear positive mode, allowing the interrogation of high molecular weight samples. The acceleration voltage was set by default to $20 \mathrm{kV}$ with an extraction delay time of $200 \mathrm{~ns}$ and a laser frequency of
$50 \mathrm{~Hz}$. The analysis was carried out in the mass range between 4000 and 20,000 $\mathrm{Da}$. To ensure an even measurement covering the entire area of the sample spot, a netlike pattern of 100 equally distributed locations was defined. At 50 of these profiles, 10 consecutive laser shots were applied, adding up to 500 laser shots per sample spot. The ion gate was set at $3900 \mathrm{Da}$ and the pulsed extraction optimized at 12,000 $\mathrm{Da}$. The generated raw spectra were processed with the Launchpad ${ }^{\text {Th }}$ version 2.9 software (Shimadzu-Biotech Corp., Kyoto, Japan) using the following settings: the advanced scenario was 
chosen from the parent peak cleanup menu, peak width was set to 80 channels, smoothing filter width to 50 channels, baseline filter width to 500 channels and the threshold apex was chosen as the peak detection method. The threshold apex peak detection was set as a dynamic type and the offset was set to $0.020 \mathrm{mV}$ with a response factor of 1.2. The processed spectra were exported as peak lists with $\mathrm{m} / \mathrm{z}$ values for each peak and signal intensity in the ASCII format. Each target plate was externally calibrated using the reference spectra of Escherichia coli strain DH5 $\alpha$.

\section{Spectral analysis: superspectrum design \& validation}

The generated mass spectra were exported to Launch$\operatorname{pad}^{\mathrm{Tw}}$, quality-checked by eye and repeat measurements carried out if necessary. Mass spectra of reviewed spectra were then transferred in ASCII format to the spectral archive and microbial identification system (SARAMIS ${ }^{\mathrm{Tm}}$ ) (AnagnosTec, Potsdam-Golm, Germany). A biomarker mass pattern, called superspectrum (SSp.) was calculated for each tick species using the SARAMIS ${ }^{\text {тा }}$ SuperSpec$\operatorname{tra}^{\mathrm{Tx}}$ tool. To that end, the quadruplicate mass lists of four ticks were consolidated, peaks with a relative intensity below $1 \%$ removed and average masses calculated with an error of $800 \mathrm{ppm}$. Masses of high species specificity were determined by comparison between the different tick SSp. and weighted manually.

In the validation step, using the SARAMIS ${ }^{\mathrm{mi}}$ identification tool, quadruplicate mass spectra of the remaining ticks were matched against the previously designed reference superspectra. A match between a SSp. and acquired mass spectra was regarded as positive at $75 \%$ identity or higher. Accordingly, each mass spectrum achieved either a single match, sharing $\geq 75 \%$ identity with only one SSp., a multiple match if sharing $\geq 75 \%$ identity with more than one SSp., or no match if the $75 \%$ identity threshold with no SSp. was reached. In case of a multiple match, the SSp. achieving the highest identity score was assumed the valid match. Subsequently, a given tick was assigned a final ID (i.e. species identification) when two criteria were met: (1) at least one of the four mass spectra matched to a SSp. and (2) assigned matches amongst the four mass spectra were not in conflict with each other.

\section{Ethical statement}

ILRI's Institutional Animal Care and Use Committee (IACUC) governed the use of cattle and rabbits for the maintenance of the lab tick colonies (approval no. 2010.1). The collection of field ticks did not involve endangered or protected species.

\section{Results}

Morphological identification of field ticks

Morphological identification grouped the ticks collected from vegetation and animals into 14 different species (Table 1). While five of these species were already represented by the laboratory colonies, nine species were exclusively covered by field ticks only. These species included Amblyomma gemma (21), Amblyomma hebraeum (4), Hyalomma anatolicum anatolicum (13), Hyalomma dromedarii (3), Hyalomma marginatum rufipes (18), Hyalomma truncatum (14), $R$. praetextatus (8), Rhipicephalus pulchellus (37) and $R$. simus (17).

Laboratory reared and field ticks combined, the 398 ticks grouped into 14 species within three genera, namely Amblyomma (3), Hyalomma (4) and Rhipicephalus (5)/ Rhipicephalus (Boophilus) (2). $51.3 \%(204 / 398)$ of the ticks belonged to the genus Rhipicephalus, $16.3 \%$ (65/ 398 ) to Rhipicephalus (Boophilus), $16.3 \%$ (65/398) to Amblyomma and $16.1 \%(64 / 398)$ to Hyalomma. Six tick species including $R$. appendiculatus (87), $R$. evertsi evertsi (55), $R$. (B.) decoloratus (41), A. variegatum (40) and $R$. pulchellus (37) represented $65.3 \%$ of the collection (Table 1).

\section{COl gene sequencing}

For a total of 33 ticks, COI gene sequences were obtained (Table 2). No unspecific amplification occurred for the negative controls included in each PCR amplification run. The sequenced amplicons - with the exception of three ticks where no consensus sequence could be determined - were all approximately 700 bp in size, and the sequences were used for comparison against entries at GenBank and/or BOLD. Since there are no COI gene sequences for A. gemma currently deposited in GenBank, specimen identity for these ticks was assigned solely based on the BOLD entries. Two ticks morphologically identified as $A$. hebraeum matched clearly with reference records of $A$. gemma in the BOLD database (identity scores of 100 and $99.70 \%$ ). At the same time, the identity shared with NCBI reference sequences for $A$. hebraeum was only $89 \%$. The whole group of four specimens morphologically determined as $A$. hebraeum, were henceforth assigned as $A$. gemma. The morphologically unidentified Hyalomma sp. was clearly determined as $H$. dromedarii, with four COI sequenced ticks matching with high scores to the respective reference records in both databases. The species designation was adopted accordingly for the further course of this study. Two members of the morphologically identified $R$. simus ticks both matched with the $R$. simus reference sequence (AF132840.1) present in NCBI with a score of $92 \%$ (data not shown) and with a slightly higher score (94.5\%) to $R$. praetextatus in the BOLD database. Higher molecular identity ( $99 \%$ with only $67 \%$ query cover) was achieved 
Table 2 Tabular overview of 33 ticks additionally identified by COI molecular typing

\begin{tabular}{|c|c|c|c|c|c|c|}
\hline & & & Morphological identification & BOLD identification & GenBank identification & \\
\hline Tick ID & COI gene length [bp] & Origin & Species ID & Species ID (Identity) & Species ID (Accession Nr.) & Identity \\
\hline 154 & 711 & Field & A. gemma & A. gemma (99.80 \%) & no reliabe ID & \\
\hline 183 & 688 & Field & A. gemma & A. gemma (100 \%) & no reliabe ID & \\
\hline 32 & 687 & Field & A. hebraeum & A. gemma (100 \%) & no reliabe ID & \\
\hline 109 & 686 & Field & A. hebraeum & A. gemma (99.70 \%) & no reliabe ID & \\
\hline 36 & 692 & Lab & A. variegatum & A. variegatum (100 \%) & A. variegatum (GU062743.1) & $97 \%$ \\
\hline 86 & $651^{a}$ & Field & A. variegatum & A. variegatum (99.70 \%) & A. variegatum (GU062743.1) & $99 \%$ \\
\hline 242 & 702 & Lab & A. variegatum & A. variegatum (100 \%) & A. variegatum (GU062743.1) & $97 \%$ \\
\hline 27 & 688 & Field & H. dromedarii & H. dromedarii (100\%) & H. dromedarii (AJ437071.1) & $99 \%$ \\
\hline 74 & 688 & Field & H. dromedarii & H. dromedarii (100\%) & H. dromedarii (AJ437061.1) & $99 \%$ \\
\hline 118 & 680 & Field & H. dromedarii & H. dromedarii (100\%) & H. dromedarii (AJ437071.1) & $99 \%$ \\
\hline 34 & 688 & Lab & H. sp. & H. dromedarii (100\%) & H. dromedarii (AJ437061.1) & $99 \%$ \\
\hline 112 & 686 & Lab & H. sp. & H. dromedarii (100\%) & H. dromedarii (AJ437061.1) & $99 \%$ \\
\hline 194 & 680 & Lab & H. sp. & H. dromedarii (100\%) & H. dromedarii (AJ437061.1) & $99 \%$ \\
\hline 207 & 686 & Lab & H. sp. & H. dromedarii (100\%) & H. dromedarii (AJ437061.1) & $99 \%$ \\
\hline \multirow[t]{2}{*}{139} & 689 & Field & H. m. rufipes & H. m. rufipes (99.84 \%) & H. m. rufipes (AJ437100.1) & $99 \%$ \\
\hline & & & & & H. truncatum (AJ437088.1) & $99 \%$ \\
\hline 359 & 688 & Field & H. m. rufipes & H. m. rufipes (99.12 \%) & H. m. rufipes (AJ437095.1) & $99 \%$ \\
\hline 72 & 684 & Field & H. truncatum & H. truncatum (99\%) & H. truncatum (AJ437084.1) & $97 \%$ \\
\hline 361 & $555^{\mathrm{a}}$ & Field & H. truncatum & H. truncatum (98 \%) & H. truncatum (AJ437084.1) & $97 \%$ \\
\hline 38 & 693 & Lab (Kiambu) & R. appendiculatus & R. appendiculatus (99.50 \%) & R. appendiculatus (AF132833.1) & $97 \%$ \\
\hline 121 & 687 & Lab (Muguga) & R. appendiculatus & R. appendiculatus (99.50 \%) & R. appendiculatus (AF132833.1) & $98 \%$ \\
\hline 198 & 679 & Lab (Muguga) & R. appendiculatus & R. appendiculatus (99.50 \%) & R. appendiculatus (AF132833.1) & $98 \%$ \\
\hline 225 & 687 & Field & R. appendiculatus & R. appendiculatus (99.85\%) & R. appendiculatus (AF132833.1) & $99 \%$ \\
\hline 146 & 673 & Field & R. (B.) decoloratus & R. (B.) decoloratus (100\%) & R. (B.) decoloratus (AF132826.1) & $99 \%$ \\
\hline 278 & 690 & Lab & R. (B.) decoloratus & R. (B.) decoloratus (99.85 \%) & R. (B.) decoloratus (AF132826.1) & $99 \%$ \\
\hline 165 & $585^{a}$ & Lab & R. (B.) microplus & R. (B.) microplus (100\%) & R. (B.) microplus (KC503261.1) & $100 \%$ \\
\hline 377 & 689 & Field & R. (B.) microplus & R. (B.) microplus (100\%) & R. (B.) microplus (KC503261.1) & $99 \%$ \\
\hline 170 & 694 & Field & R. evertsi evertsi & R. evertsi evertsi (100 \%) & R. evertsi evertsi (AF132835.1) & $98 \%$ \\
\hline 275 & 688 & Lab & R. evertsi evertsi & R. evertsi evertsi (100 \%) & R. evertsi evertsi (AF132835.1) & $98 \%$ \\
\hline 370 & 688 & Field & R. praetextatus & no reliabe ID & no reliabe ID & \\
\hline 396 & 702 & Field & R. praetextatus & no reliabe ID & no reliabe ID & \\
\hline 397 & 702 & Field & R. pulchellus & R. pulchellus (98 \%) & R. pulchellus (AY008682.1) & $99 \%$ \\
\hline 29 & 701 & Field & R. simus & no reliabe ID & no reliabe ID & \\
\hline 115 & 690 & Field & R. simus & no reliabe ID & no reliabe ID & \\
\hline
\end{tabular}

${ }^{a}$ no consensus sequence

Marked in bold: Ticks later used for SSp. design

No reliable ID: Identity with top match $<97 \%$

with deposited partial COI gene sequences (472 bp) of Rhipicephalus muhsamae. The two ticks morphologically identified as $R$. praetextatus matched with a relatively high identity of $96 \%$ (data not shown) to a $R$. simus record on NCBI and with $100 \%$ identity to unpublished $R$. praetextatus records on BOLD. Given these uncertain molecular results and the limited reference records available, the specimens of the $R$. simus and $R$. praetextatus batch were merged to one group and the species designation changed to $R$. simus group. Extraction of DNA qualitatively sufficient for COI gene sequencing failed with all specimens of $H$. anatolicum anatolicum. The morphologically assigned species identity of these ticks could therefore not be confirmed on molecular basis. The COI gene sequence of a tick (ID 139, Table 2) morphologically identified as $H$. marginatum 
rufipes was identified with equal score as $H$. marginatum rufipes and $H$. truncatum on GenBank. Since the same COI sequence matched highest to $H$. marginatum rufipes record on the BOLD database, the species identity as initially determined on a morphological basis was assumed correct. Taking together the molecular results, all ticks morphologically identified as A. hebraeum, Hyalomma sp., $R$. simus and $R$. praetextatus were reclassified to $A$. gemma, $H$. dromedarii and $R$. simus group, respectively. The species identity of $H$. anatolicum anatolicum could not be confirmed due to insufficient quality of genomic DNA. All the remaining tick species that were assigned morphologically were confirmed by our molecular analysis.

\section{MALDI-TOF MS analysis Spectra quality}

A total of 1592 single mass spectra were generated, corresponding to 398 ticks measured in quadruplicate. Inadequate spectral quality was assessed visually and accordingly 55 ticks were re-measured and integrated into the sample set. Seventeen ticks were excluded from the study after the first MALDI-TOF MS measurement since the poor overall state of the specimens did not allow for the generation of qualitatively adequate mass spectra. Among the excluded ticks were four ticks of the $R$. simus group batch that were partially overgrown by fungus. The entire collection (13 specimens) of $H$. anatolicum anatolicum for which also preceding DNA extraction had failed, were stored in leaky microtubes and as a result completely desiccated. The remaining 1524 mass spectra (381 ticks) used for the subsequent analyses presented a good signalto-noise ratio and clear protein peaks, mostly distributed between 4000 to 13,000 Da (Additional file 1: Figure S1). The number of protein peaks per spectrum ranged from 14 to 145 , with an average peak count of 42.5 .

\section{Intra species reproducibility of mass spectra}

Visual inspection of spectral profiles revealed a generally highly similar mass fingerprint shared between individuals of the same species. Simultaneously, mass spectra were still heterogeneous on species level with missing or exclusive mass peaks only present in certain specimens or spectral profiles (Fig. 2). However, comparative analysis of the spectral profiles with SARAMIS ${ }^{\text {ma }}$ confirmed that few major protein peaks remained highly conserved within a given species (Fig. 2). A significant difference between the mass spectra of male and female ticks of the same species could not be observed. This is in line with what has been reported in other studies [31, 32].

\section{Inter species specificity of mass spectra}

To assess the interspecies specificity of the mass spectra generated by MALDI-TOF MS, the spectral profiles of the previous molecularly identified 33 ticks were subjected to cluster analysis (Fig. 3). As expected, the spectra derived from the same tick e.g. the technical replicates each clustered together in closest proximity. This was not the case for the mass profiles of just one tick (specimen no. 029). Importantly, within this set of ticks, all spectra derived from specimens of the same species seemed to share distinct masses that separated them clearly from the remaining tick species.

\section{Definition of superspectra identifying East African tick species}

After COI molecular and MALDI-TOF MS analysis, our specimen collection was slightly reduced from 398 to 381 ticks, now grouping into ten different species and the ambiguous $R$. simus group. Incorporating these results, SSp. were designed from a total of 48 ticks (Table 3). The mass profiles derived from the Kiambu laboratory tick strain that has been maintained for many years at the ILRI tick unit showed consistently high deviations from the other $R$. appendiculatus profiles (indicated in Fig. 3). This lead us to define a distinct SSp. designated as $R$. appendiculatus II exclusively covering this batch of ticks. The final $12 \mathrm{SSp}$. designed in this study were based on 192 mass spectra of 48 individual ticks and consisted of 14 to 30 individual protein masses (Table 3). In addition to including 24 COI typed specimens to the SSp. design, we also incorporated ticks representative of the diversity within a given species. This led to the inclusion of both field and laboratory ticks in some cases and to the inclusion of ticks with distinct mass patterns in other cases.

\section{Validation of defined superspectra for tick identification}

After removal of the 48 ticks used to build the reference spectra, 333 ticks remained for the validation step of the generated SSp. Our approach failed to assign an ID to 13 specimens, 319 ticks were correctly identified and only one tick was assigned a wrong ID. This corresponded to an overall sensitivity of $96.1 \%$ and a specificity of $99.7 \%$ (Table 4). Among the correctly identified ticks, 182 or $57.1 \%$ matched with the correct SSp. in all four acquired mass spectra (indicated as $4 \times$ CC in Table 4). Sixty-six (20.7\%) ticks matched with three mass spectra to the correct SSp. while one mass spectrum resulted in no match. Twenty-three $(7.2 \%)$ ticks matched with two mass spectra to the correct SSp. while two mass spectra achieved no match. Nineteen $(6.0 \%)$ ticks matched with three mass spectra to the correct SSp. while one mass spectrum reached multiple matches, with the correct SSp. as the top match. The remaining 29 (9.1\%) ticks were positively identified, with their mass spectra matching in other combinations (indicated as "other" in Table 4). 


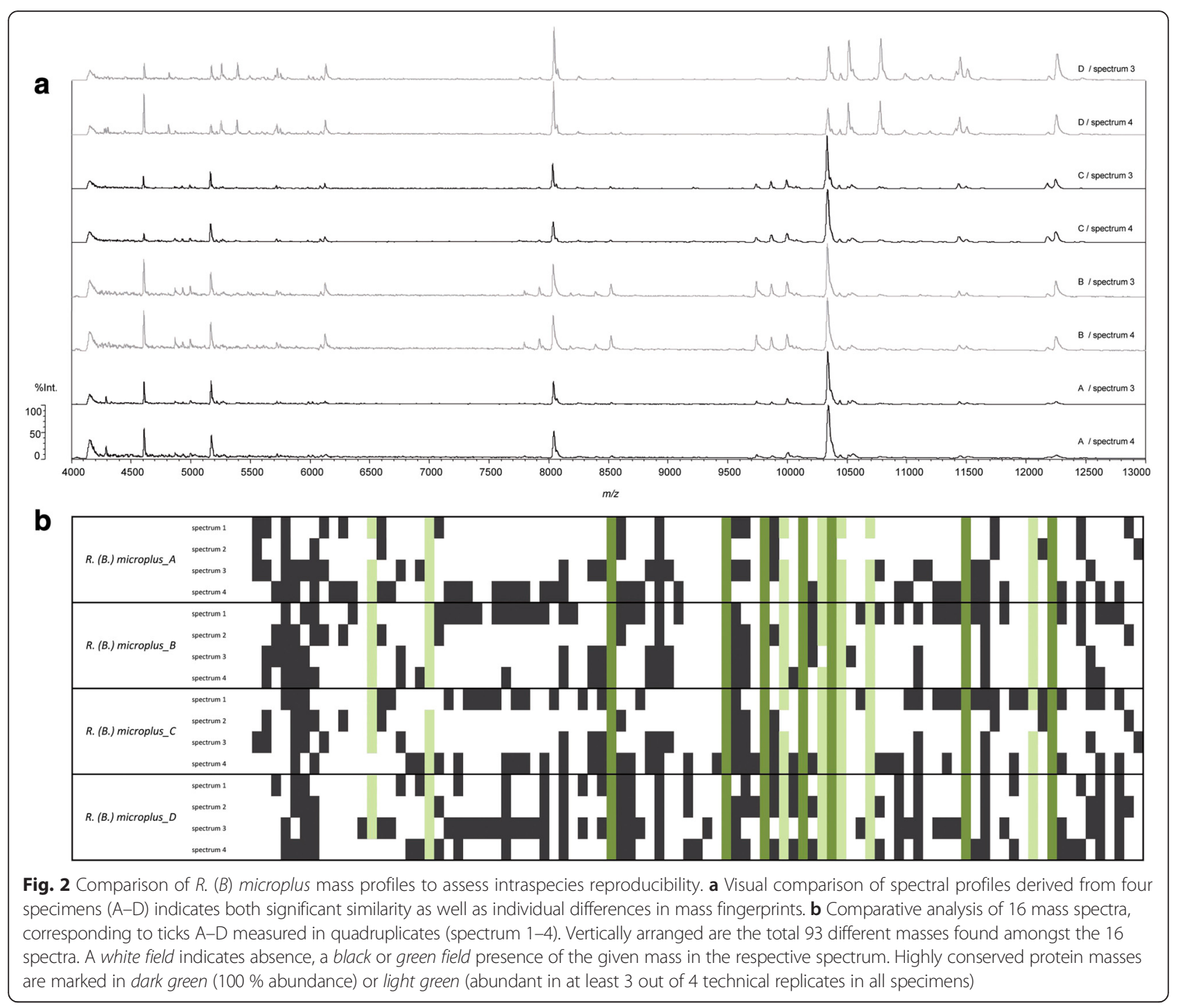

Among the successfully identified ticks, the sensitivity of our approach was lowest for A. gemma (81\%) where a total of 21 ticks were used for validation and the $R$. appendiculatus ticks derived from the Kiambu stock (80\%), where only five ticks were used for validation. The sole tick that was assigned a false species ID, was a specimen morphologically identified as $R$. evertsi evertsi. While three of this tick's mass spectra did not achieve a match at all, one mass spectrum was marginally similar (78 \%, data not shown) to the $R$. simus group SSp. The mass spectra of the 13 ticks that could not be assigned to any SSp. and the spectrum of the wrongly assigned tick were inspected visually to assess the spectral quality. It appeared that most spectra displayed alterations like distorted or shifted mass peaks. The species identity of the wrongly identified $R$. evertsi evertsi specimen could not be verified on a molecular basis, since the extracted gDNA was not qualitatively sufficient for PCR. Three ticks with no SSp. ID $(1 \times H$. dromedarii and $2 \times A$. gemma) were subjected to molecular COI analysis. The morphologically assigned species identities of all three specimens (Fig. 4; tick no. 95, 60 and 30) were confirmed on molecular basis.

The 48 ticks initially used to build the reference SSp. were not considered for the study validation. These mass spectra were later experimentally validated against all SSp. (data not shown). All mass spectra of the ticks were, as one would expect, correctly identified with their corresponding SSp.

\section{Discussion}

Several genera of ixodid tick genera co-exist throughout Eastern Africa, including Hyalomma, Amblyomma and Rhipicephalus. Precise and timely data on tick population distribution and size in a given geographical area are required to model epidemiological trends of tick- 


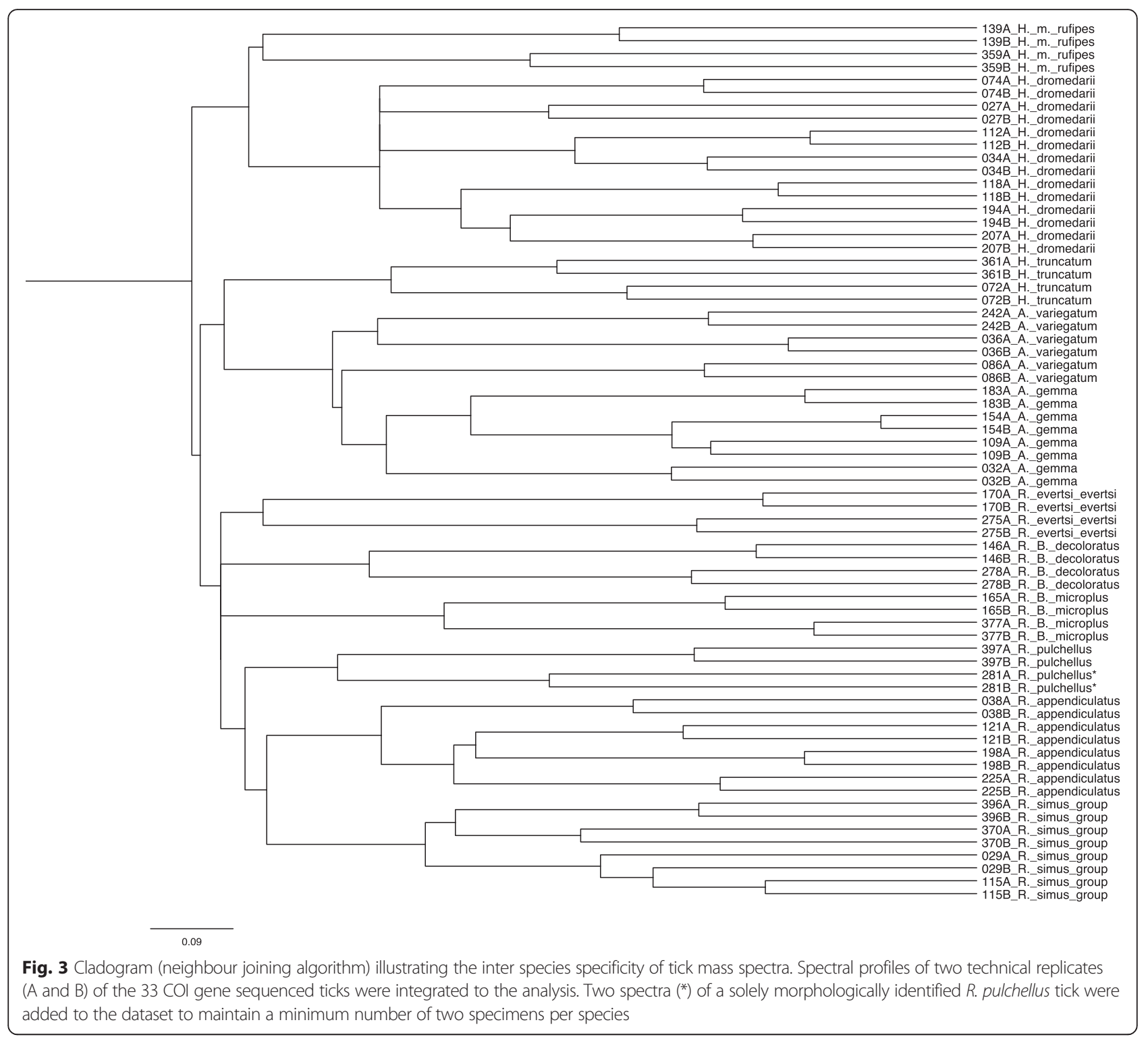

borne diseases and formulate effective control strategies $[1,33]$. However, tick identification by morphology can be limited by a lack of expertise, the need of several male specimens, whereas immature tick stages are difficult to identify by morphology alone [6].

In this study, MALDI-TOF MS was used to investigate a collection of laboratory-bred and field-collected afrotropical ixodid ticks with the aim of confirming their identity and establishing a reference MS spectra index designated as SSp.

The quality of the spectra generated for the vast majority of the ticks included in this study corresponded to what has been observed in similar studies with a range of arthropod vectors including European tick species [15, 16], tsetse flies [14], mosquitoes [12] and midges [31].
We found that spectra quality, overall protein mass counts and the molecular weight range that can be determined mainly depend on the initial quality of the sample itself. Seventeen ticks that were improperly stored and overgrown by fungus, or that were completely desiccated needed to be removed from this study due to inadequate quality of mass spectra obtained. A less apparent factor negatively affecting the overall spectral quality seems to be long-term storage of tick specimens in ethanol [31]. This could have been a factor in the failure to correctly identify 14 ticks, where most mass profiles revealed alterations in spectral quality on close examination. Poor peak resolution, diffuse signals in the low molecular weight range, and a shift in peak patterns were the most common characteristics observed in spectra from the unidentified specimens. Additional 
Table 3 Superspectra designed in this study

\begin{tabular}{|c|c|c|c|}
\hline Name of SSp. & $\begin{array}{l}\text { Condensed } \\
\text { Mass Count }\end{array}$ & N (COl-typed) & Origin $(\mathrm{N})$ \\
\hline Amblyomma gemma & 24 & $4(2)$ & Field (4) \\
\hline $\begin{array}{l}\text { Amblyomma } \\
\text { variegatum }\end{array}$ & 30 & $4(2)$ & Lab (3), Field (1) \\
\hline Hyalomma dromedarii & 29 & $4(4)$ & $\operatorname{Lab}(4)$ \\
\hline $\begin{array}{l}\text { Hyalomma marginatum } \\
\text { rufipes }\end{array}$ & 24 & $4(2)$ & Field (4) \\
\hline Hyalomma truncatum & 23 & $4(2)$ & Field (4) \\
\hline $\begin{array}{l}\text { Rhipicephalus } \\
\text { (Boophilus) decoloratus }\end{array}$ & 14 & $4(1)$ & Lab (2), Field (2) \\
\hline $\begin{array}{l}\text { Rhipicephalus } \\
\text { (Boophilus) microplus }\end{array}$ & 16 & $4(2)$ & Lab (3), Field (1) \\
\hline $\begin{array}{l}\text { Rhipicephalus } \\
\text { appendiculatus I }\end{array}$ & 21 & $4(3)$ & $\begin{array}{l}\text { Lab Muguga (2), } \\
\text { Field (2) }\end{array}$ \\
\hline $\begin{array}{l}\text { Rhipicephalus } \\
\text { appendiculatus ॥ }\end{array}$ & 18 & $4(1)$ & Lab Kiambu (4) \\
\hline $\begin{array}{l}\text { Rhipicephalus evertsi } \\
\text { evertsi }\end{array}$ & 19 & $4(2)$ & Lab (2), Field (2) \\
\hline Rhipicephalus pulchellus & 26 & $4(1)$ & Field (4) \\
\hline $\begin{array}{l}\text { Rhipicephalus simus } \\
\text { group }\end{array}$ & 18 & $4(2)$ & Field (4) \\
\hline Total & & $48(24)$ & Lab (20), Field (28) \\
\hline
\end{tabular}

Table 4 Validation of SSp. with 333 ticks

\begin{tabular}{|c|c|c|c|c|c|c|c|c|c|c|}
\hline \multirow[t]{2}{*}{ Tick species name } & \multirow[t]{2}{*}{$\mathrm{N}$} & \multicolumn{5}{|c|}{ True ID assigned ${ }^{a}$} & \multirow{2}{*}{$\begin{array}{l}\text { No ID } \\
\text { assigned }^{\text {a }}\end{array}$} & \multirow{2}{*}{$\begin{array}{l}\text { Wrong ID } \\
\text { assigned }^{\mathrm{a}}\end{array}$} & \multirow[t]{2}{*}{ Sensitivity } & \multirow[t]{2}{*}{ Specificity } \\
\hline & & $4 \times C C$ & $3 \times C C 1 \times N$ & $2 \times C C 2 \times N$ & $\begin{array}{l}3 \times C C 1 \times \\
C\end{array}$ & other & & & & \\
\hline Amblyomma gemma & 21 & 4 & 4 & 5 & 0 & 4 & 4 & 0 & $81.00 \%$ & $100.00 \%$ \\
\hline Amblyomma variegatum & 36 & 16 & 9 & 4 & 4 & 3 & 0 & 0 & $100.00 \%$ & $100.00 \%$ \\
\hline Hyalomma dromedarii & 15 & 11 & 1 & 0 & 1 & 0 & 2 & 0 & $86.70 \%$ & $100.00 \%$ \\
\hline Hyalomma marginatum rufipes & 14 & 4 & 4 & 2 & 0 & 2 & 2 & 0 & $85.70 \%$ & $100.00 \%$ \\
\hline Hyalomma truncatum & 10 & 2 & 4 & 2 & 1 & 0 & 1 & 0 & $90.00 \%$ & $100.00 \%$ \\
\hline $\begin{array}{l}\text { Rhipicephalus (Boophilus) } \\
\text { decoloratus }\end{array}$ & 37 & 25 & 7 & 1 & 2 & 2 & 0 & 0 & $100.00 \%$ & $100.00 \%$ \\
\hline $\begin{array}{l}\text { Rhipicephalus (Boophilus) } \\
\text { microplus }\end{array}$ & 20 & 6 & 8 & 0 & 3 & 3 & 0 & 0 & $100.00 \%$ & $100.00 \%$ \\
\hline Rhipicephalus appendiculatus & 74 & 53 & 13 & 3 & 2 & 2 & 1 & 0 & $98.60 \%$ & $100.00 \%$ \\
\hline $\begin{array}{l}\text { Rhipicephalus appendiculatus } \\
\text { (Kiambu) }\end{array}$ & 5 & 4 & 0 & 0 & 0 & 0 & 1 & 0 & $80.00 \%$ & $100.00 \%$ \\
\hline Rhipicephalus evertsi evertsi & 51 & 34 & 9 & 1 & 4 & 1 & 1 & 1 & $98.00 \%$ & $98.00 \%$ \\
\hline Rhipicephalus pulchellus & 33 & 15 & 5 & 4 & 2 & 7 & 0 & 0 & $100.00 \%$ & $100.00 \%$ \\
\hline \multirow[t]{2}{*}{ Rhipicephalus simus group } & 17 & 8 & 2 & 1 & 0 & 5 & 1 & 0 & $94.10 \%$ & $100.00 \%$ \\
\hline & & 182 & 66 & 23 & 19 & 29 & & & & \\
\hline Total & 333 & 319 & & & & & 13 & 1 & $96.10 \%$ & $99.70 \%$ \\
\hline
\end{tabular}

${ }^{a}$ For each tick, four technical replicate mass spectra were matched against designed SSp. and a final ID assigned accordingly CC: one correct SSp. matching; C: multiple SSp. matching, correct SSp. as top match; N: no matching SSp other: true ID was assigned based on a different combination
MALDI-TOF MS analysis with ticks plucked directly from animals or collected from vegetation without prior storage in ethanol could support these assumptions and reveal if spectral quality and taxonomic resolution can be enhanced significantly using freshly collected ticks.

In the majority of cases with samples sufficiently conserved, identification of ticks by matching their mass profiles against reference SSp. proved to be very robust. This was demonstrated by the high sensitivity (96.1\%) with which tick species were identified successfully. This is a significant achievement considering the large tick collection size, with some of the species represented by specimens originating from very different laboratory or field environments.

Together with COI gene sequences, a number of interesting conclusions can be inferred from the present study. The known problem of morphological tick species misidentification can be exemplified by two of our findings. (a) COI-typing of two ticks morphologically identified as $A$. hebraeum, revealed that the specimens were in fact members of the closely related A. gemma. This was for the most part resolved by our MALDI-TOF MS analyses, where three of the tick samples were identified clearly as A. gemma. The fourth tick, although showing high similarity with the A. gemma SSp., displayed spectral alterations and was not assigned any ID. (b) Similarly, a batch of ticks included into our collection clearly 


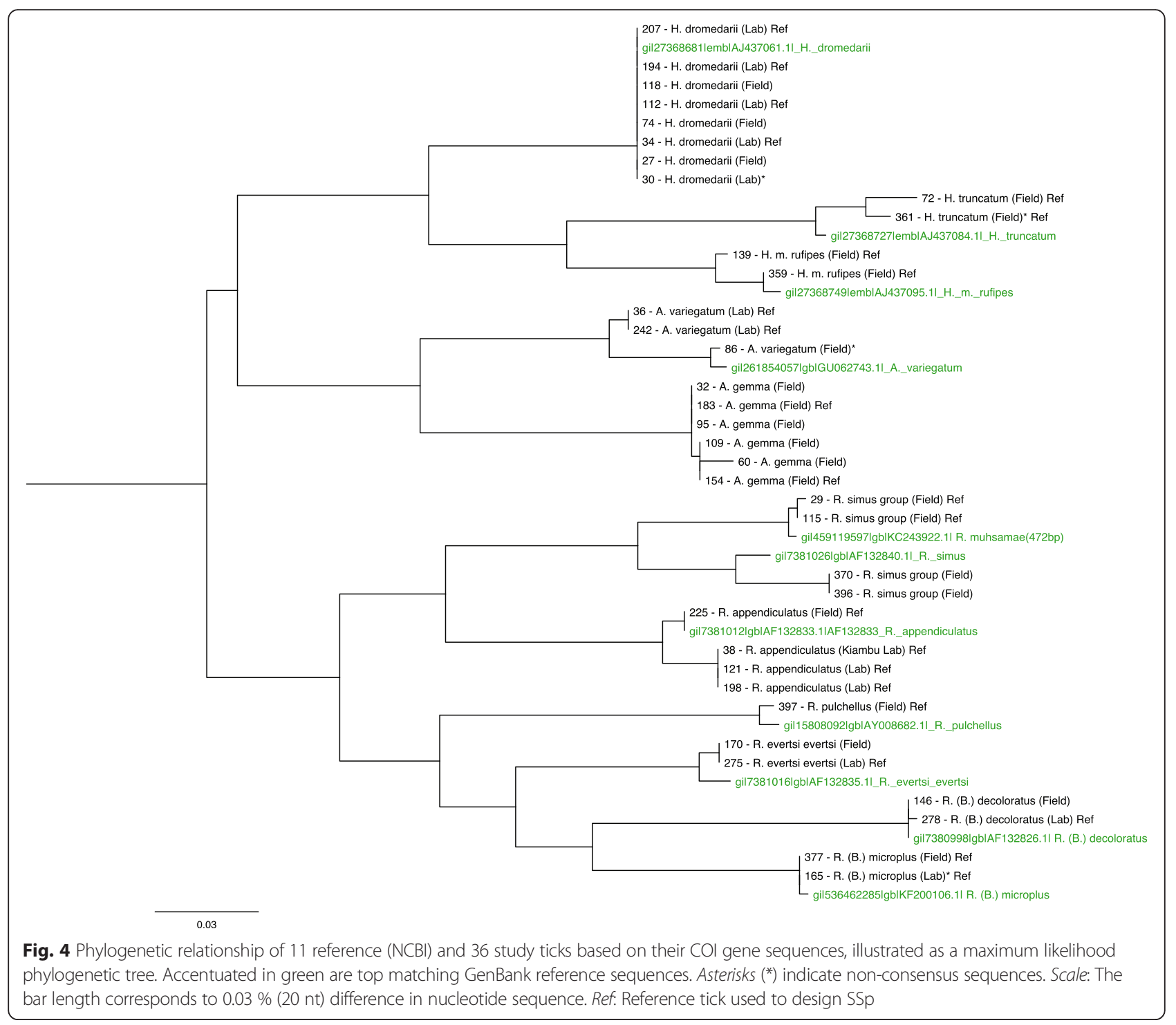

belonged to the genus Hyalomma. However, the absence of any reference specimen did not allow reliable morphological species identification. COI gene sequencing and MALDI-TOF MS both convincingly identified these ticks as $H$. dromedarii. These examples confirm the value of MALDI-TOF MS for resolution of tick taxonomic ambiguities. MALDI-TOF MS can provide improved and fast discrimination, especially when morphological examination is insufficient for a clear species designation.

The limitations of conventional tick typing are not restricted to the morphological approach but can extend to molecular techniques such as sequencing of the mitochondrial COI gene. This issue has been highlighted by the example of genetic hybridization occurring amongst members of the genus Hyalomma as described by Rees et al. [34]. While individuals of the species H. truncatum,
$H$. dromedarii and $H$. marginatum rufipes are well differentiated both morphologically and genetically, sexual reproduction between members of these species can occur, resulting in hybrid offspring. Such intermediate individuals (e.g. NCBI record AJ437088.1 in Table 2) still display the distinct paternal morphological features while possessing the maternally inherited mtDNA genotype. The use of COI sequencing on its own can therefore result in misclassification of such specimens. It will be the subject of further research to establish how the mass spectra of hybrid ticks differ from the parental protein fingerprint and to what extent MALDI-TOF MS can serve as monitoring tool for following the gene flow amongst different tick species.

One unresolved issue in African tick taxonomy was highlighted by our findings regarding the ticks 
morphologically assigned as $R$. praetextatus and $R$. simus. The ongoing debate, as to which of these species is distributed where in East-Africa is based largely on the fact that they can not be easily separated morphologically [5]. Defining the accurate spread of $R$. simus and $R$. praetextatus is further complicated by the co-occurrence of other, highly similar species including $R$. lunulatus and $R$. muhsamae known to be present in the same East African habitats [5, 35]. The fact, that $R$. simus has been described to be restricted to Southern Africa $[4,5]$ suggested early on that our $R$. simus field isolates from Kenya were mistaken with a morphologically highly similar species. This was supported by the COI gene analysis, which grouped this ticks closer to $R$. praetextatus (BOLD, 94 \% identity) and $R$. muhsamae (GenBank, $99 \%$ identity and $67 \%$ query cover) than to R. simus (GenBank, $92 \%$ identity and $99 \%$ query cover). The sequence data was equally unclear for our $R$. praetextatus specimens, with both high matches to unpublished records of $R$. praetextatus reference sequences on BOLD (100\% identity) and $R$. simus in GenBank (96\% identity, $98 \%$ query cover). A phylogenetic maximum-likelihood analysis of all COI nucleotide sequences derived in this study and reference records from GenBank (Fig. 4), supports these inferences regarding $R$. simus and $R$. praetextatus. Although there appears to be a clear molecular boundary between the analyzed ticks with a suggested close proximity of the $R$. simus ticks (specimen no. 29 and 115) to R. muhsamae, the limited reference records available do not allow a conclusive answer regarding the true identity of our ticks. We therefore merged these ticks to one group defined as $R$. simus group, enveloping the tick species $R$. simus, $R$. praetextatus and $R$. muhsamae, as previously suggested by Walker, Keirans and Horak [5].

Whether MALDI-TOF MS analysis can distinguish between these three tick species, where current COI, $12 \mathrm{~S}$ and ITS2 molecular data is non-conclusive (E. Kanduma and R. Bishop, unpublished data), requires further investigation with representative specimens from all three species. It is however worth noting that our phylogenetic cluster analysis of four specimens designated as members of the $R$. simus group indicated potential differences between the spectral profiles (Fig. 3). Further studies will be needed to conclusively confirm the value of MALDI-TOF MS in discriminating between the species of the $R$. simus group.

The Kiambu $R$. appendiculatus specimens, where only five ticks were available for validation, and the ticks belonging to A. gemma were detected with the lowest sensitivity by our SSp. approach. The failure in species ID assignment for these specimens might partially be explained by the negative effect of long-term storage in ethanol as discussed before. Additionally, we hypothesized that intraspecies genetic heterogeneity could be increased in these two sets of ticks, leading to stronger diversity in spectral fingerprints. Phylogenetic analysis of the COI gene sequences does not support this theory (Fig. 4). The A. gemma ticks among each other, as well as the $R$. appendiculatus ticks of both Muguga and Kiambu stock shared almost identical COI nucleotide sequences. Continuative studies, incorporating freshly plucked ticks, will help to determine to what extent the overall sensitivity of a SSp. based identification approach can still be improved.

Looking ahead, the potential applications of MALDITOF MS as a tick species typing tool are diverse, ranging from pathogen and vector epidemiological monitoring for disease outbreak detection, to following consequences of climate change and its influence on changing patterns of tick distribution and its associated disease risks as described [36]. Furthermore, the SSp. established here provide the basis to move towards simultaneous characterization of African tick vectors and pathogens transmitted by MALDI-TOF MS, as has been shown with Rickettsia [37]. Another immediate use of this technique would be monitoring the spread of the invasive single host tick $R$. (B.) microplus [38]. This tick is both more adaptable to changing environments than native species like $R$. (B.) decoloratus and has greater potency in transmission of protozoan and bacterial pathogens, including Babesia bigemina, Babesia bovis and Anaplasma marginale [39].

\section{Conclusions}

In summary, our study demonstrated the applicability of MALDI-TOF MS as a suitable tool for East African tick identification. The processing steps of the ticks for MALDI-TOF MS are straightforward, with little time and human and equipment resources needed. The rapid generation of mass spectra profiles and their automated, immediate comparison against pre-designed reference SSp. allow high-throughput measurement of large numbers of samples. We identified the quality of the samples used as the main limiting factor for the MALDI-TOF MS analyses. Whenever possible, tick material collected freshly from the field should be analyzed. The negative impact of sample storage under ethanol for limited periods of time should be evaluated carefully, since this would increase applicability to large tick collections sampled across Africa. Under good conditions of sample storage, MALDI-TOF MS can generate highly distinctive mass profile patterns that will allow precise and rapid monitoring of tick populations, species movements, pathogen transmission and host feeding preferences on a large-scale. 


\section{Additional file}

Additional file 1: Figure S1. Comparison of MALDI-TOF MS spectral profiles, indicating distinct mass peak patterns among the different tick genera Amblyomma, Hyalomma, Rhipicephalus and Rhipicephalus (Boophilus). The spectra illustrated in the figure cover a mass range between 4000 to $18,000 \mathrm{Da}$. The relative peak intensities are indicated on the $y$-axis. (PDF $143 \mathrm{~kb}$ )

\section{Abbreviations}

BOLD: Barcode of Life Database; bp: base pair; COl: cytochrome c oxidase l; DNA: deoxyribonucleic acid; ILRI: International Livestock Research Institute; NCBI: National Center Bioinformatics; nt: nucleotide; MALDI: matrix-assisted laser desorption/ionization; MS: mass spectrometry; PCR: polymerase chain reaction; ppm: parts per million; SSp.: superspectrum; sp.: species; TOF: timeof-flight.

\section{Competing interests}

The authors declare that they have no competing interests.

\section{Authors' contributions}

EGK, SM and NG collected tick specimens and carried out the morphological identification of samples. VP supported the MALDI-TOF MS project design and data interpretation and JR conducted the MALDI-TOF MS analysis. NG and JR carried out the molecular genetic studies, participated in the sequence alignment and drafted the manuscript. CD, CO and RPB conceived of this study, and participated in its design and coordination and helped to draft the manuscript. All authors read and approved the final manuscript.

\section{Acknowledgements}

We would like to thank Christoph Stalder (Swiss TPH, Basel, Switzerland) for technical advice in DNA extraction from ticks and Roxanne Mouchet (Mabritec AG, Riehen, Switzerland) for assistance in pre-processing and MALDI-TOF MS analysis of ticks. Further gratitude is expressed to Susan Njenga (ILRI Research Method Group, Nairobi, Kenya) for the assistance in generating the tick distribution map, Edward Kariuki of Kenya Wildlife Service (KWS) for valuable discussion on tick identification by morphology and finally the ILRI Kapiti ranch staff for assistance during field sampling. Esther Kanduma was supported financially by Biosciences eastern and central Africa (BecA), the German Academic Exchange Service (DAAD) and the African Women in Agricultural Research and Development (AWARD).

\section{Author details}

${ }^{1}$ International Livestock Research Institute (ILRI), PO Box 30709-00100, Nairobi, Kenya. ${ }^{2}$ Department of Medical Parasitology and Infection Biology, Clinical Immunology Unit, Swiss Tropical and Public Health Institute (Swiss TPH), Socinstr. 57, CH 4002 Basel, Switzerland. ${ }^{3}$ University of Basel, Petersplatz 1, CH 4003 Basel, Switzerland. ${ }^{4}$ Mabritec SA, Lörracherstrasse 50, CH 4125 Riehen, Switzerland. ${ }^{5}$ Department of Veterinary Microbiology and Pathology, Washington State University, PO Box 647040, Pullman, WA 99163, USA. ${ }^{6}$ Biosciences eastern and central Africa - International Livestock Research Institute (BecA-ILRI) Hub, PO Box 3070900100 Nairobi, Kenya. ${ }^{7}$ Department of Biochemistry, School of Medicine, University of Nairobi, PO Box 30197, Nairobi, Kenya.

Received: 16 December 2015 Accepted: 4 March 2016 Published online: 15 March 2016

\section{References}

1. Jongejan F, Uilenberg G. The global importance of ticks. Parasitology. 2004; 129 Suppl:S3-14.

2. Kivaria FM. Estimated direct economic costs associated with tick-borne diseases on cattle in Tanzania. Trop Anim Health Prod. 2006:38:291-9.

3. Estrada-Peña A, Farkas R, Jaenson TGT, Koenen F, Madder M, Pascucci I, Salman M, Tarrés-Call J, Jongejan F. Association of environmental traits with the geographic ranges of ticks (Acari: Ixodidae) of medical and veterinary importance in the western Palearctic. A digital data set. Exp Appl Acarol. 2013:59:351-66.
4. Walker AR, Bouattour A, Camicas JL, Estrada-Pena A, Horak IG, Latif A, Pegram RG, Preston PM. Ticks of domestic animals in Africa: a guide to identification of species. Edinburgh: Bioscience Reports; 2003.

5. Walker JB, Keirans JE, Horak IG. The Genus Rhipicephalus (Acari, Ixodidae): A Guide to the Brown Ticks of the World. Cambridge University Press; 2000

6. Guglielmone AA, Robbins RG, Apanaskevich DA, Petney TN, Estrada-Peña A, Horak IG. The hard ticks of the world. Dordrecht: Springer Netherlands; 2014.

7. Araya-Anchetta A, Busch JD, Scoles GA, Wagner DM. Thirty years of tick population genetics: a comprehensive review. Infect Genet Evol. 2015;29:164-79.

8. Kanduma EG, Mwacharo JM, Mwaura S, Njuguna JN, Nzuki I, Kinyanjui PW, Githaka N, Heyne H, Hanotte O, Skilton RA, Bishop RP. Multi-locus genotyping reveals absence of genetic structure in field populations of the brown ear tick (Rhipicephalus appendiculatus) in Kenya. Ticks Tick-Borne Dis. 2015;7:26-35.

9. Will KW, Rubinoff D. Myth of the molecule: DNA barcodes for species cannot replace morphology for identification and classification. Cladistics. 2004;20:47-55.

10. Shen $Y-Y$, Chen X, Murphy RW. Assessing DNA barcoding as a tool for species identification and data quality control. PLoS One. 2013:8:e57125.

11. DeSalle R, Egan MG, Siddall M. The unholy trinity: taxonomy, species delimitation and DNA barcoding. Philos Trans R Soc B Biol Sci. 2005;360:1905-16.

12. Yssouf A, Parola P, Lindström A, Lilja T, L'Ambert G, Bondesson U, Berenger J-M, Raoult D, Almeras L. Identification of European mosquito species by MALDI-TOF MS. Parasitol Res. 2014;113:2375-8.

13. Schaffner F, Kaufmann C, Pflüger $\vee$, Mathis A. Rapid protein profiling facilitates surveillance of invasive mosquito species. Parasit Vectors. 2014;7:142.

14. Hoppenheit A, Murugaiyan J, Bauer B, Steuber S, Clausen P-H, Roesler U. Identification of Tsetse (Glossina spp.) using matrix-assisted laser desorption/ ionisation time of flight mass spectrometry. PLoS Negl Trop Dis. 2013;7:e2305.

15. Yssouf A, Flaudrops C, Drali R, Kernif T, Socolovschi C, Berenger J-M, Raoult D, Parola P. Matrix-assisted laser desorption ionization-time of flight mass spectrometry for rapid identification of tick vectors. J Clin Microbiol. 2013;51:522-8.

16. Karger A, Kampen H, Bettin B, Dautel H, Ziller M, Hoffmann B, Süss J, Klaus C. Species determination and characterization of developmental stages of ticks by whole-animal matrix-assisted laser desorption/ionization mass spectrometry. Ticks Tick-Borne Dis. 2012;3:78-89.

17. Seng P, Drancourt M, Gouriet F, La Scola B, Fournier P-E, Rolain JM, Raoult D. Ongoing revolution in bacteriology: routine identification of bacteria by matrix-assisted laser desorption ionization time-of-flight mass spectrometry. Clin Infect Dis Off Publ Infect Dis Soc Am. 2009;49:543-51.

18. Bishop RP, Hemmink JD, Morrison WI, Weir W, Toye PG, Sitt T, Spooner PR, Musoke AJ, Skilton RA, Odongo DO. The African buffalo parasite Theileria sp. (buffalo) can infect and immortalize cattle leukocytes and encodes divergent orthologues of Theileria parva antigen genes. Int J Parasitol Parasites Wildl. 2015;4:333-42.

19. Mans BJ, Pienaar R, Latif AA. A review of Theileria diagnostics and epidemiology. Int J Parasitol Parasites Wildl. 2015;4:104-18 [Including Articles from "International Congress on Parasites of Wildlife", Pp. 49-158].

20. Sitt T, Poole EJ, Ndambuki G, Mwaura S, Njoroge T, Omondi GP, Mutinda M, Mathenge J, Prettejohn G, Morrison WI, Toye P. Exposure of vaccinated and naive cattle to natural challenge from buffalo-derived Theileria parva. Int J Parasitol Parasites Wildl. 2015:4:244-51.

21. Bailey KP: Notes on the rearing of Rhipicephalus appendiculatus and their infection with Theileria parva for experimental transmission. Bull Epizoot Dis Afr. 1960:33-64

22. Irvin AD, Brocklesby DW. Rearing and maintaining Rhipicephalus appendiculatus in the laboratory. Ji Nan Idoon Animat Technol. 1970;20:106-12.

23. Kanduma EG, Mwacharo JM, Sunter JD, Nzuki I, Mwaura S, Kinyanjui PW, Kibe M, Heyne H, Hanotte O, Skilton RA, Bishop RP. Micro- and minisatelliteexpressed sequence tag (EST) markers discriminate between populations of Rhipicephalus appendiculatus. Ticks Tick-Borne Dis. 2012;3:128-36.

24. Folmer O, Black M, Hoeh W, Lutz R, Vrijenhoek R. DNA primers for amplification of mitochondrial cytochrome c oxidase subunit I from diverse metazoan invertebrates. Mol Mar Biol Biotechnol. 1994;3:294-9.

25. Stucky BJ. SeqTrace: a graphical tool for rapidly processing DNA sequencing chromatograms. J Biomol Tech JBT. 2012;23:90-3.

26. Tamura K, Stecher G, Peterson D, Filipski A, Kumar S. MEGA6: Molecular Evolutionary Genetics Analysis version 6.0. Mol Biol Evol. 2013;30:2725-9.

27. Sayers EW, Barrett T, Benson DA, Bryant SH, Canese K, Chetvernin V, Church DM, DiCuccio M, Edgar R, Federhen S, Feolo M, Geer LY, Helmberg W, Kapustin $Y$, Landsman D, Lipman DJ, Madden TL, Maglott DR, Miller V, Mizrachi I, Ostell J, Pruitt KD, Schuler GD, Sequeira E, Sherry ST, Shumway M, 
Sirotkin K, Souvorov A, Starchenko G, Tatusova TA, et al. Database resources of the National Center for Biotechnology Information. Nucleic Acids Res. 2009;37(Database issue):D5-15.

28. Ratnasingham S, Hebert PDN. BOLD: The Barcode of Life Data System (http://www.barcodinglife.org). Mol Ecol Notes. 2007;7:355-64.

29. Rambaut A. FigTree v1.4.2. Tree figure drawing tool. 2014. Available: http:// tree.bio.ed.ac.uk/software/figtree/. Accessed Sept 2015.

30. Kaufmann C, Schaffner F, Ziegler D, Pflüger V, Mathis A. Identification of field-caught Culicoides biting midges using matrix-assisted laser desorption/ ionization time of flight mass spectrometry. Parasitology. 2012;139:248-58.

31. Kaufmann C, Ziegler D, Schaffner F, Carpenter S, Pflüger V, Mathis A. Evaluation of matrix-assisted laser desorption/ionization time of flight mass spectrometry for characterization of Culicoides nubeculosus biting midges. Med Vet Entomol. 2011;25:32-8.

32. Campbell PM. Species differentiation of insects and other multicellular organisms using matrix-assisted laser desorption/ionization time of flight mass spectrometry protein profiling. Syst Entomol. 2005;30:186-90.

33. George JE, Pound JM, Davey RB. Chemical control of ticks on cattle and the resistance of these parasites to acaricides. Parasitology. 2004;129(Suppl):S353-66.

34. Rees DJ, Dioli M, Kirkendall LR. Molecules and morphology: evidence for cryptic hybridization in African Hyalomma (Acari: Ixodidae). Mol Phylogenet Evol. 2003:27:131-42.

35. Pegram RG, Walker JB, Clifford CM, Keirans JE. Comparison of populations of the Rhipicephalus simus group: R. simus, R. praetextatus, and R. muhsamae (Acari: Ixodidae). J Med Entomol. 1987;24:666-82.

36. Gray JS, Dautel H, Estrada-Peña A, Kahl O, Lindgren E. Effects of climate change on ticks and tick-borne diseases in Europe. Interdiscip Perspect Infect Dis. 2009; 2009:e593232

37. Yssouf A, Almeras L, Terras J, Socolovschi C, Raoult D, Parola P. Detection of Rickettsia spp in ticks by MALDI-TOF MS. PLoS Negl Trop Dis. 2015;9:e0003473.

38. Chevillon C, de Garine-Wichatitsky M, Barré N, Ducornez S, de Meeûs T. Understanding the genetic, demographical and/or ecological processes at play in invasions: lessons from the southern cattle tick Rhipicephalus microplus (Acari: Ixodidae). Exp Appl Acarol. 2013;59:203-18.

39. Jonsson NN, Bock RE, Jorgensen WK. Productivity and health effects of anaplasmosis and babesiosis on Bos indicus cattle and their crosses, and the effects of differing intensity of tick control in Australia. Vet Parasitol. 2008; 155:1-9.

\section{Submit your next manuscript to BioMed Central and we will help you at every step:}

- We accept pre-submission inquiries

- Our selector tool helps you to find the most relevant journal

- We provide round the clock customer support

- Convenient online submission

- Thorough peer review

- Inclusion in PubMed and all major indexing services

- Maximum visibility for your research

Submit your manuscript at www.biomedcentral.com/submit

C Biomed Central 